\title{
CREEP OF A SILICON NITRIDE UNDER VARIOUS SPECIMEN/LOADING CONFIGURATIONS
}

\author{
Sung R. Choi, Lynn M. Powers, Frederic A. Holland, and John P. Gyekenyesi \\ NASA Glenn Research Center, Cleveland, Ohio 44135, USA
}

\begin{abstract}
Extensive creep testing of a hot-pressed silicon nitride (NC132) was performed at $1300^{\circ} \mathrm{C}$ in air using five different specimen/loading configurations, including pure tension, pure compression, four-point uniaxial flexure, ball-on-ring biaxial flexure, and ring-on-ring biaxial flexure. Nominal creep strain and its rate for a given nominal applied stress were greatest in tension, least in compression, and intermediate in uniaxial and biaxial flexure. Except for the case of compressive loading, nominal creep strain generally decreased with time, resulting in less-defined steady-state condition. Of the four different creep formulations - power-law, hyperbolic sine, step, and redistribution models - the conventional power-law model still provides the most convenient and reasonable means to estimate simple, quantitative creep parameters of the material. Predictions of creep deformation for the case of multiaxial stress state (biaxial flexure) were made based on pure tension and compression creep data by using the design code CARES/Creep.
\end{abstract}

\section{INTRODUCTION}

Advanced ceramics are candidate materials for hightemperature structural applications in gas turbine engines and heat recovery systems. The two major limitations of these materials, slow crack growth and creep, are generally encountered in high-temperature applications. At higher temperatures, particularly at lower applied stress, enhanced creep takes place in the form of permanent deformation and/or damage accumulation, leading to loss of structural integrity and possibly the eventual rupture of components. Therefore, for higher-temperature applications, the accurate determination of creep behavior including creep and rupture parameters and associated mechanisms is important for ensuring structural integrity and component life. Because of difference in creep between tension and compression [1-3], parameters that are derived from relatively easy flexural testing using the conventional simple beam theory, which assumes the neutral axis to be fixed, can be misleading. Many structural components are subjected to multiaxial stresses, typically combined with tensile and compressive stresses. Therefore, in order to accurately predict or estimate creep deformation and rupture of multiaxially stressed components, creep and rupture parameters of a material should be determined individually both in tension and in compression, together with an appropriate prediction/design methodology.

The immediate objective of this work was to develop and conduct creep testing to determine creep behavior of a hotpressed silicon nitride under various loading configurations at $1300^{\circ} \mathrm{C}$ in air. The loading configurations used in this study include pure tension, pure compression, four-point uniaxial flexure, ball-on-ring biaxial flexure, and ring-on-ring biaxial flexure. Creep displacements for each specimen/loading configuration were determined as a function of time with several different levels of applied loads. NASA Glenn Research Center has developed an analytical methodology and an integrated design program named CARES/Creep (Ceramics Analysis and Reliability Evaluation of Structures/Creep) to be used for predicting the creep deformation and nupture life of structural ceramic components $[4,5]$. The second objective of this work was to validate the CARES/Creep design code on the basis of the creep database generated from the experimental work. This was done by predicting creep deformation subjected to multiaxial (biaxial) stress state based on the basis of pure tension and pure compression data and by comparing with actual biaxial flexure data.

\section{EXPERIMENTAL PROCEDURES}

The material used in this work was a hot-pressed silicon nitride (designated as NC132, Vintage 1990, fabricated by Norton Co., Northboro, MA) containing $\mathrm{MgO}$ as primary sintering aid. This material was chosen since it has shown for decades a controlled uniformity in mechanical and physical properties such as hardness, fracture toughness, strength, and slow crack growth, etc. The material also has been extensively characterized previously to determine fatigue and/or creep life prediction parameters as a candidate gas turbine material [6-8].

Creep testing was performed in ATS dead-weight creep frames at $1300^{\circ} \mathrm{C}$ in air using five different specimens/oading configurations, including pure tension, pure compression, fourpoint uniaxial flexure, ball-on-ring biaxial flexure, and ring-onring biaxial flexure. The test specimen/loading configurations used in creep testing are depicted in Figure 1. Detailed experimental procedures and techniques can be found elsewhere [9]. Briefly, in pure tension, the dog-bone-shaped, pin-loaded tension specimens with round cross-sections were used that were nominally $2.0 \mathrm{~mm}$ in diameter, $70 \mathrm{~mm}$ in overall length, and $20 \mathrm{~mm}$ in gage length. The pin holes in the tension test specimens were also tapered to minimize misalignment. Creep displacements were monitored using a scanning laser extensometry system (LaserMike, Dayton, $\mathrm{OH}$ ) with two $\mathrm{SiC}$ flags (typically apart from 12 to $15 \mathrm{~mm}$ ) that were attached to the gage section of each test specimen by friction. Six different nominal tensile stresses ranging from 10 to $81 \mathrm{MPa}$ were utilized. Typically one specimen was used at each applied load. Testing was conducted in accordance with ASTM Test Method C1291 [10].

In pure compression testing, cylindrical test specimens 3.5 $\mathrm{mm}$ in diameter and $7.5 \mathrm{~mm}$ in height (= gage length) were used. The choice of such dimensions for the compression test specimens was intended to minimize undesirable phenomena

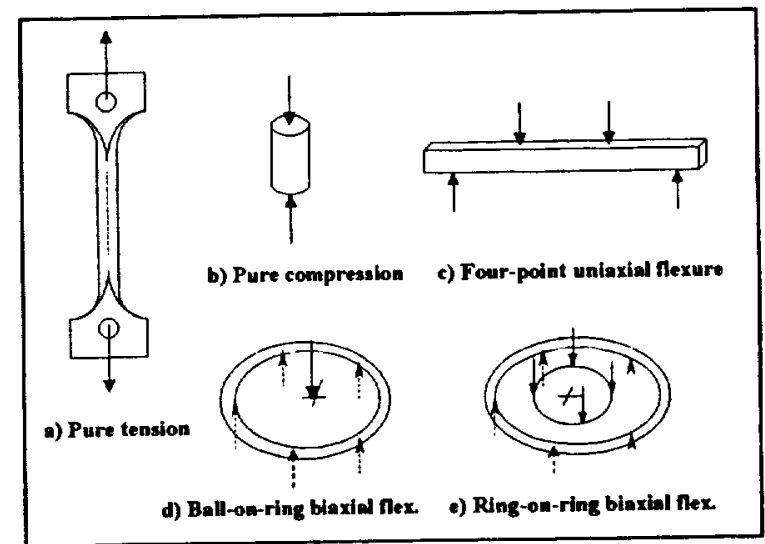

Figure 1. Five different specimen/laading configurations used in this study: (a) pure tension; (b) pure compression; (c) fourpoint uniaxial flexure; (d) ball-on-ring biaxial flexure; (c) ringon-ring biaxial flexure. 
such as buckling and barreling, with a suggested ratio (height to diameter, $h / d$ ) of 1.5 to 2.0 [11]. Since creep deformation of ceramic materials, in general, is significantly smaller in compression than in tension, higher applied stresses, ranging from $160 \mathrm{MPa}$ to $630 \mathrm{MPa}$, were used in compression testing. A total of five different nominal applied stresses were used, with one specimen tested at each stress. The creep displacement measurements in the gage section were made using a three-probe LVDT extensometer placed between the two ends of each test specimen.

In four-point uniaxial flexure testing, flexure beam specimens were loaded in a $\mathrm{SiC}$ four-point flexure fixture with $20 \mathrm{~mm}$ - inner and $40 \mathrm{~mm}$ - outer spans. The nominal dimensions of test specimens were $3 \mathrm{~mm}$ by $4 \mathrm{~mm}$ by $50 \mathrm{~mm}$, respectively, in height, width and length. $A$ total of 7 different nominal stresses, ranging from 29 to $162 \mathrm{MPa}$, were used, with one test specimen tested at each nominal stress. An LVDT probe was placed underneath the center point (tension side) of each test specimen to measure creep deflection.

In ball-on-ring biaxial flexure testing, 2-mm-thick, $45-\mathrm{mm}$ diameter disk specimens were loaded in the biaxial test fixtures. The lower support fixture consisted of a total of nine 9-mm-diameter $\mathrm{SiC}$ balls mounted on the flat $\mathrm{SiC}$ support block, evenly spaced peripherally to form a pitch diameter of $40 \mathrm{~mm}$. The upper 9-mni-diameter SiC loading ball was slightly ground to form a small, flat, round surface of $1.31 \mathrm{~mm}$ diameter that was to be in contact with the center of each test specimen. The center creep deflections of test specimens were determined with an LVDT probe. A total of four applied loads ranging from 45 to $182 \mathrm{~N}$, which corresponded to nominal maximum stresses of 29 to $115 \mathrm{MPa}$, calculated based on idealized elasticity solution [12], were utilized, with one disk specimen tested at each applied load.

Finally, in ring-on-ring biaxial testing, each disk specimen was loaded between the upper loading and lower support biaxial flexure fixtures. The upper loading fixture consisted of seven 9-mm-diameter $\mathrm{SiC}$ balls, evenly spaced peripherally forming a pitch diameter of $15 \mathrm{~mm}$. The lower support fixture was the same as that used in the ball-on-ring biaxial flexure testing. The dimensions of test disk specimens used in ring-onring biaxial flexure were the same as those used in ball-on-ring biaxial flexure. The center deflection of each test specimen was monitored using an LVDT probe. A total of four applied loads ranging from 200 to $565 \mathrm{~N}$, with corresponding nominal maximum stresses (calculated based on Ref. 12) ranging from 29 to $81 \mathrm{MPa}$, were used. One disk specimen was tested at each applied load.

\section{RESULTS AND DISCUSSION}

\section{EXPERIMENTAL RESULTS}

A summary of creep deflections (or deflections) as a function of time determined from the five different specimen/loading configurations is presented in Figure 2. The end point of each curve corresponds to the end of the test. No test specimen failed up to its time of interruption except for the test specimen fractured in compression testing with a high nominal stress of $630 \mathrm{MPa}$. In most cases, surfaces of the tested specimens revealed some degree of oxidation, depending on the test time period. However, no visible signs of the microcracks associated with enhanced creep were observed on the specimens, even after the removal of their oxide layers.

In tension creep testing, test times spanned from 20 days at $81 \mathrm{MPa}$ to 60 days for $41 \mathrm{MPa}$. The displacement curves for the specimens tested at 10 and $28 \mathrm{MPa}$ seemed to show the steadystate creep regions where displacement rate remained relatively constant. By contrast, the curves for the specimens tested at 57 and $81 \mathrm{MPa}$ showed no well-defined steady-state region, but rather a change in displacement rates with time. In compression creep testing, most of the curves (except the one at $500 \mathrm{MPa}$ ) exhibited the steady-state creep region, which is in somewhat good contrast with the tensile creep curves. However, no distinct primary region was observed for most of the test specimens. At the highest compressive stress of $630 \mathrm{MPa}$, the specimen failed in a manner similar to fast fracture, leaving many tiny fragments. The data for this specimen were not used in the analysis.
In spite of appreciable creep deflection in uniaxial flexure, no specimen failed before the interruption of the testing period, which ranged from 17 days for the highest nominal stress of $162 \mathrm{MPa}$ to about 100 days for the lowest nominal stress of 29 $\mathrm{MPa}$. Regardless of the nominal applied stresses, creep rate changed with time, so that no definite steady-state creep region could be determined. Since no explicit secondary steady-state creep region existed, a clear-cut transition between the primary and secondary regions was hardly definable.

As in tension, uniaxial flexure, and ring-on-ring biaxial flexure testing, no test (disk) specimen in ball-on-ring biaxial flexure testing failed before the end of the testing period. The testing period ranged from 20 days for the highest nominal stress of $81 \mathrm{MPa}$ to 100 days for the nominal stress of $41 \mathrm{MPa}$. Al the lower nominal stresses of 41 and $29 \mathrm{MPa}$, the primary creep region seemed to be accompanied by the secondary, steady-state creep region. However, it is not clear yet whether the primary or the secondary creep region exists in the curves for higher nominal stresses of 57 and $81 \mathrm{MPa}$. It was observed from the crept disk specimens that the loading ball was in nearly full contact rather than in ring contact with the test specimen surfaces, which was attributed to the increased plasticity and creep of test specimens during the tests. Hence, the use of the stress formula [12] based on the full-contact assumption seemed to be justified in this context. llowever, the exactricss of the stresses actually distributed in the disk specimens during creep testing is in question and consequently is another separate issue.

The testing period in ring-on-ring biaxial creep ranged from 10 to 12 days for the lower nominal stresses $\leq 57 \mathrm{MPa}$ (but for 45 days for the highest nominal stress of $81 \mathrm{MPa}$ ). Considering the relatively short test times, it would be premature to draw any conclusion regarding the creep curves obtained from stresses $\leq$ $57 \mathrm{MPa}$. For the disk specimen tested at the highest nominal stress of $81 \mathrm{MPa}$, its displacement rate changed with time, making it difficult to define the primary and the secondary steady-state regions.

\section{CREEP STRAIN-CREEP STRAIN RATE}

The equations to determine creep strains for the five different specimen/loading configurations were all based on the idealized elasticity solutions. Therefore, if significant creep, plasticity, relaxation and/or a shift of neutral axis toward the compression side are present, the application of those equations to flexure loading may not be appropriate. As a result, the flexure strain and stress, calculated based on the idealized solutions, were termed in this paper 'nominal' creep strain and 'nominal' applied stress, respectively.

A typical example of test results for a given nominal applied stress is shown in Figure 3, where nominal creep strain was plotted as a function of time for different specimen-loading configurations, determined at $57 \mathrm{MPa}$. The overall nominal creep strain as well as its rate was highest for tension loading, intermediate for uniaxial flexure loading, and lowest for biaxial flexure (ball-on-ring and ring-on-ring) loading. (Of course, the lowest nominal creep strain would be for compression loading if compression data were available at $57 \mathrm{MPa}$.) The degree of constraint in creep due to the presence of compressive stress in flexure was increased from uniaxial flexure to biaxial flexure. The results of Figure 3 clearly indicate a significant difference in creep between tension and compression loading.

Since, in general, there was no explicit secondary, steadystate region (except for compression loading), the actual nominal strain rate as a function of time was determined using a best-fit nominal strain curve and then taking the derivative of the strain curve with respect to time. Although many advanced ceramics have exhibited well-defined secondary creep region, there still exist many silicon nitrides that have not revealed definite steadystate but that have exhibited a monotonic decrease in strain rate with time [13]. Particularly, a rapid decrease in strain rate from the earliest observations ( $<10^{-4}$ strain) is termed "exhaustion creep" [13]. One possible mechanism for decreases in strain rate during creep for these glass-bonded ceramics (silicon nitrides) has been attributed to a redistribution of the grain-boundary amorphous phase, that is, rearrangement of the amorphous film by viscous flow during creep. The hardening effect, a phenomenon of strain rate decreasing with time, or enhancement of creep resistance, is also manipulated as a result of grain 

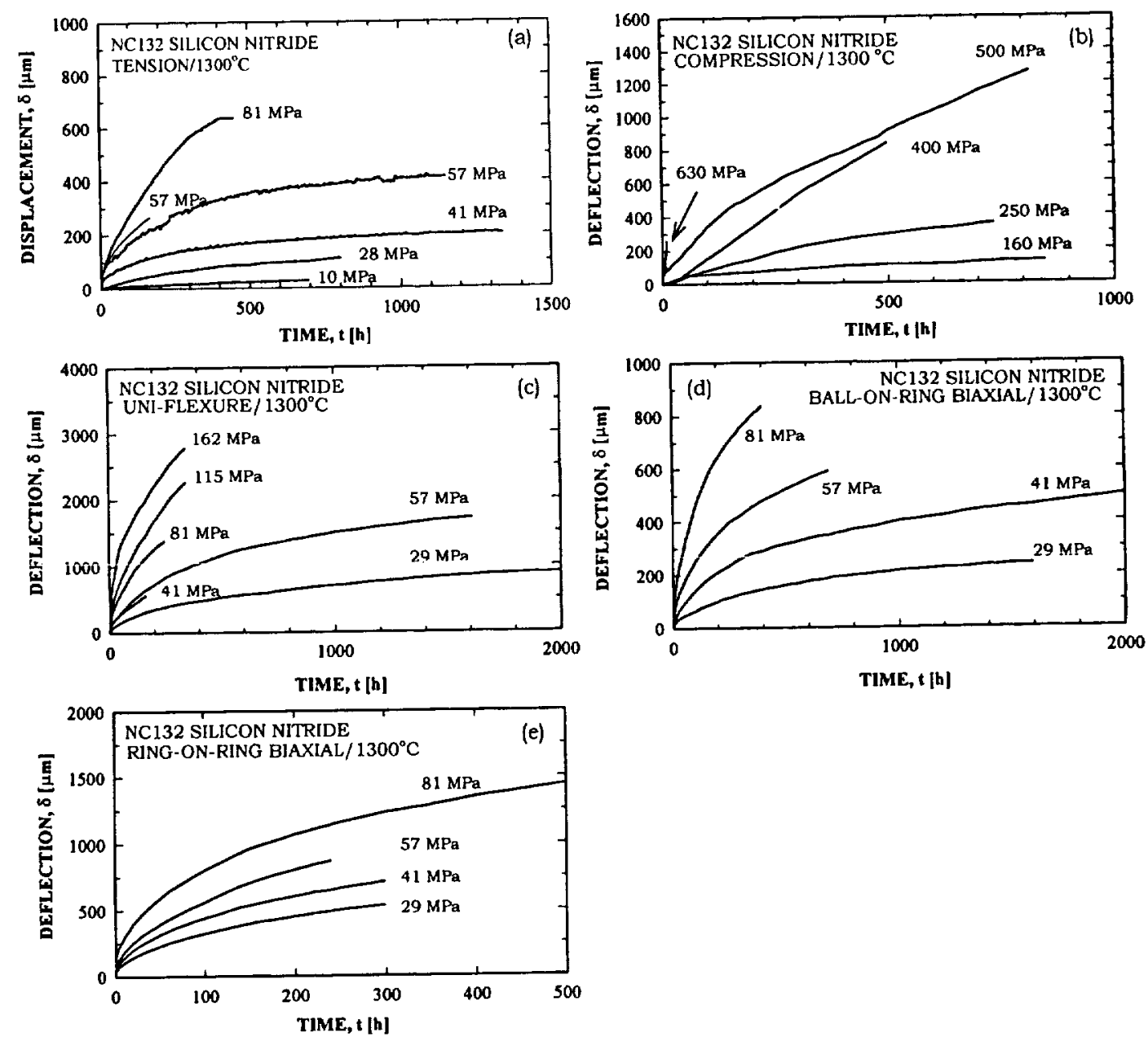

Figure 2. A summary of creep deflection (displacement) as a function of time for different levels of applied loads, determined at five different specimen/loading configurations for $\mathrm{NC132}$ silicon nitride at $1300^{\circ} \mathrm{C}$ : (a) pure tension; (b) pure compression; (c) four-point uniaxial flexure; (d) ball-on-ring biaxial flexure; (e) ring-on-ring biaxial flexure.

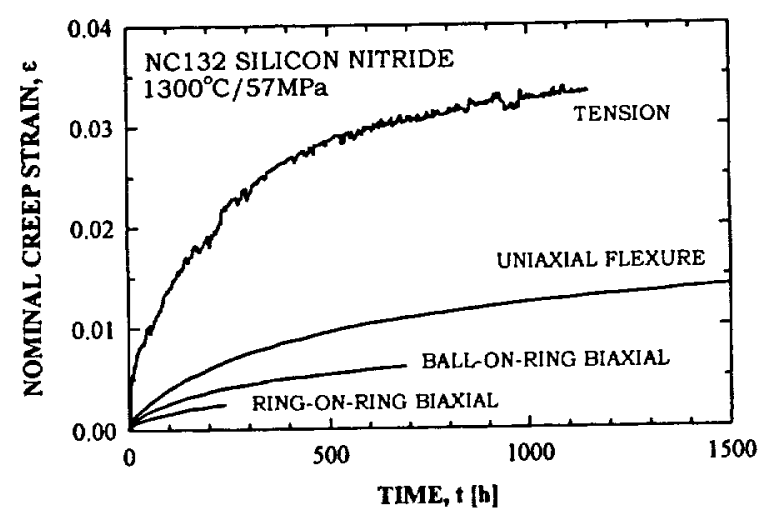

Figure 3. A comparison of nominal creep strain as a function of time determined at four different specimen/loading configurations at a nominal applied stress of $57 \mathrm{MPa}$ for $\mathrm{NC} 132$ silicon nitride at $1300^{\circ} \mathrm{C}$. 

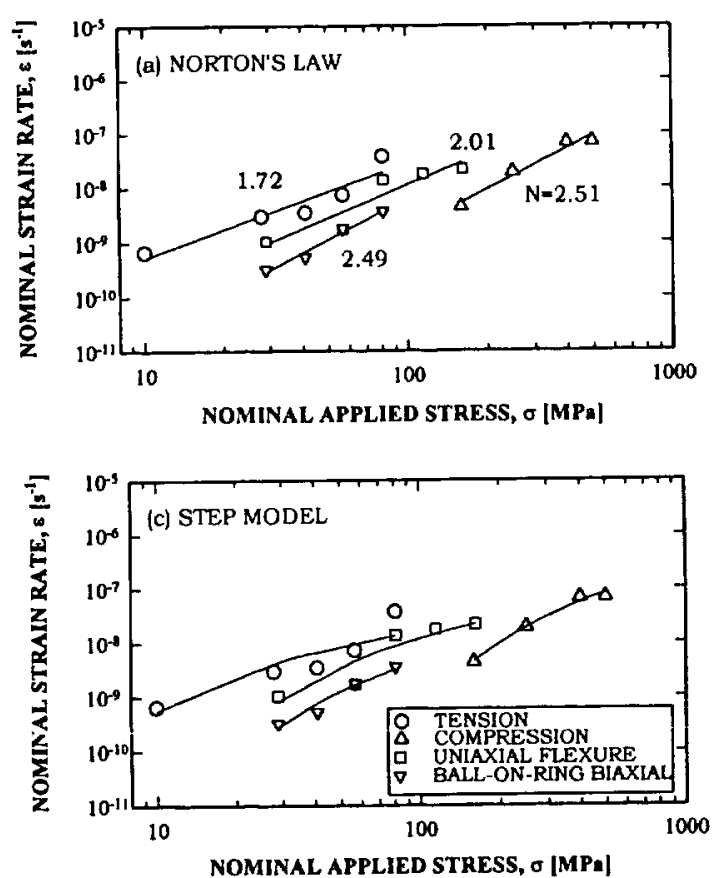
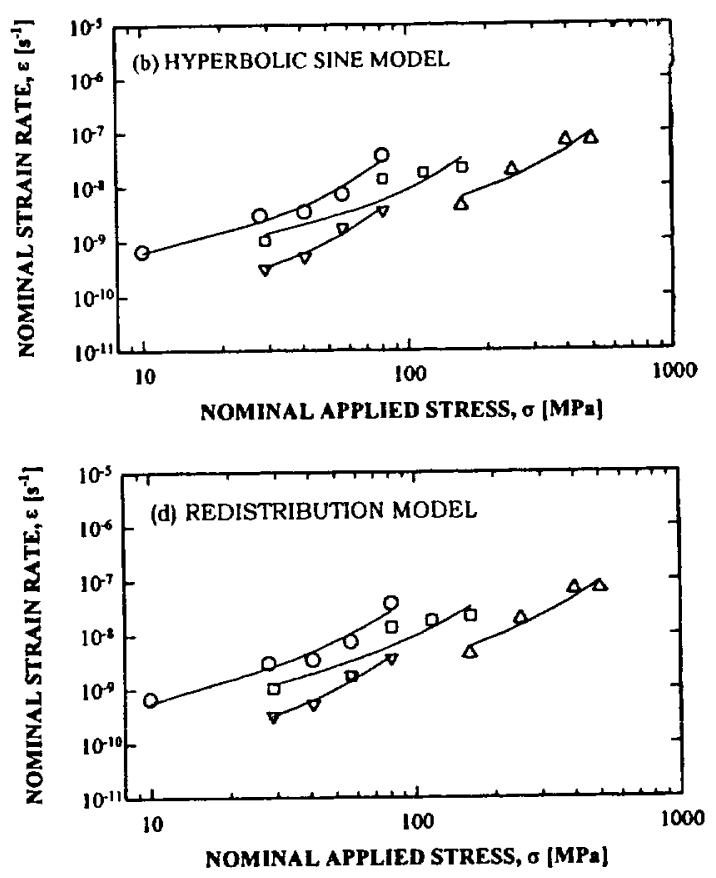

Figure 4. A summary of nominal creep strain rate as a function of nominal applied stress with different specimen/loading configurations for $\mathrm{NCl} 32$ silicon nitride at $1300^{\circ} \mathrm{C}$, fitted to four different creep models: (a) power-law (Norton) model; (b) hyperbolic sine model; (c) step model; (d) redistribution model.

contact during deformation [13].

When creep strain curves exhibit neither steady-state nor tertiary region, the minimum creep strain rate at the end of the 'extensive' primary creep is often used synonymously as the steady-state rate. The decrease in nominal strain rate observed from these experiments, however, was not significant (even after 1500 to $2000 \mathrm{~h}$ ) compared with cases in the literature in which the decrease in creep strain rate for some silicon nitrides amounted to about 2 orders of magnitude [13]. A decrease in nominal strain rate of about 1 order of magnitude was observed for cases of tension and uniaxial flexure at $57 \mathrm{MPa}$. Otherwise, the decrease was generally less than 1 order of magnitude. Therefore, a steady-state nominal creep strain rate for a given curve was approximated by averaging the nominal creep strain rates at two different times: at the start of testing, from 50 to 400 $\mathrm{h}$, and the end of testing, from 220 to $2000 \mathrm{~h}$. The choice of the start time, which was assumed to represent the initiation of steady-state region, depended on the loading condition and applied load.

\section{CREEP STRAIN-RATE VS. APPLIED STRESS}

Several models to describe creep strain rate as a function of applied stress have been proposed. In this section, some representative models such as power-law [14], hyperbolic sine $[15,16]$, step [17] and redistribution [18] models will be reviewed and applied to the experimental data. A summary of nominal creep strain rate as a function of nominal applied stress using the four models is presented in Figure 4. Note that the data on ringon-ring biaxial flexure were not included in this figure; they were produced during a test period of less than $300 \mathrm{~h}$ cannot be compared with data obtained over a longer period. There was no significant difference in curve fitting between the power-law, hyperbolic sine, and redistribution models. The hyperbolic sine model in particular yields the almost same result as the redistribution model. The power-law model shows a somewhat worse fit to the tension data at high stress, not revealing the actual curvature in the data. Similarly, the step model also gives a worse fit to the tension data, but gives a reasonably good fit to other loading configurations. It should be noted that the models employed were developed primarily for pure tension loading. Hence, strictly speaking, it is questionable whether the models would be applicable for other than tension loading, since the creep mechanism in one loading configuration may vary in different loading configurations.

In view of its mathematical simplicity, the conventional power-law model has been widely utilized for decades, regandless of the type of loading (tension, compression or flexure) for quantitative description of creep behavior of most advanced ceramic materials. Many analytical models also have been proposed on the basis of the power-law, constitutive relations. The stress exponent $N$ s in the power-law model, determined with the experimental data (see Figure 4a), were $N=$ $1.72 \pm 0.34$ in tension, $2.51 \pm 0.36$ in compression, $2.01 \pm 0.45$ in uniaxial flexure, and $2.49 \pm 0.28$ in ball-on-ring biaxial flexure. The somewhat negligible difference in stress exponent $N$ between the four loading configurations implies that the mechanisms associated with creep of this material would not be significantly different with any specimen-loading configurations. It has been observed that dislocation and cavitation mechanisms yield values of $N \approx 3-6$, diffusion creep and/or viscous flow of the glassy phase yields the value of $N \approx 1$, and grain boundary sliding results in $N \approx 2[19,20]$. Cannon and Langdon [19] showed that many silicon nitrides (and silicon carbides) exhibited a stress exponent of $N \approx 2$ regardless of tension, compression, or uniaxial flexure. The mechanism was elaborated as grain boundary sliding with intergranular cavitation.

Although the stress exponent was not significantly different between tension and compression, the difference in creep strain (and strain rate) between the two for a given applied stress was significant. The strain in tension was about 1.5 to 2 orders of magnitude greater than that in compression, if the compression data are extrapolated toward lower stresses. This difference in creep strain between tension and compression eventually results in a neutral axis shift toward the compression side of a flexure beam or disk specimen. It has been reported that flexure beam specimens of many ceramic materials have exhibited a neutral axis shift for equilibrium because of difference in creep strain, often accompanied by appreciable void and/or cavitation formation on the tension side $[1-3,21-23]$. Because of this asymmetric creep behavior, the data determined from simple uniaxial-flexure creep testing are considered inappropriate for use as design parameters of structural ceramic components. A 
recent study [24] using the data generated in this work demonstrated that with individual tension and compression creep data and taking into account the neutral-axis shift, a reasonable prediction of creep deformation in uniaxial flexure was obtained with the CARES/Creep design code. The same approach will be made for the case of more complicated multiaxial (biaxial) flexure in the next section.

\section{CARES/Creep DESIGN CODE}

The CARES/Creep integrated design computer program $[4,5]$ predicts the service life of a monolithic ceramic component as a function of component geometry and loading conditions. The CARES/Creep couples commercially available finite element programs, with design methodologies to account for creep rupture. The code is divided into two separately executable modules, CARES/CRPEST and CARES/Creep, which perform: (1) calculation of parameters from experimental data using laboratory specimens; and (2) damage evaluation of thermo-mechanically loaded components, respectively. Finite element heat transfer and nonlinear stress analyses are used to determine the temperature and stress distributions in the component. The creep life of a component is discretized into short time steps, during which the stress and strain distributions are assumed constant. The damage is calculated for each time step based on a modified Monkman-Grant creep rupture criterion. Failure is assumed to occur when the normalized accumulated damage at any point in the component is greater than or equal to unity. The corresponding time will be the creep rupture life for that component.

A schematic representation of the integrated design process is shown in Figure 5 [5]. The CARES/Creep algorithm makes use of the nonlinear stress analysis capabilities of the ANSYS finite element program. Before building a model in ANSYS, the creep response of the material must be known. An input file containing these parameters is generated by the parameter estimation module of CARES/CRPEST. This module is written in FORTRAN 77 and has as its input data from creep tests. After the parameter estimation and nonlinear analysis has been completed, the second half of the CARES/Creep program may be nun. This module is executed from within the ANSYS program and is written in APDL (ANSYS Parametric Design Language). APDL routines usually take the form of an ANSYS macro which is a sequence of ANSYS commands recorded on a file for repeated use. By recording these commands on a macro, they can be executed with one ANSYS command. When this execution is completed, a damage map of the component is displayed in the graphics window. This map consists of a contour plot of the component's damage at the time when failure has taken place, or at any design life.

The prediction of multiaxial creep deformation in ball-onring biaxial flexure was made using the CARES/Creep code, on the basis of the tension and compression creep data obtained. The finite element mesh used in this analysis is shown in Figure 6. Parameter estimations were determined with the Norton-Bailey laws. The result of predictions is presented in Figure 7, where both the predicted and experimental displacements were plotted as a function of time at four different levels of nominal applied stress. The prediction somewhat underestimates the data. Notwithstanding the discrepancy, the overall agreement in displacement between the two seems to be reasonable, in view of general observations that some degree of scatter in creep deformation even at the same applied load has been common in many ceramics. Figure 8 shows the corresponding state of stress (or stress relaxation) occurring in the biaxial disk specimen subjected to a nominal applied stress of $28 \mathrm{MPa}$. Two different times of $t=0$ and $t=$ $1000 \mathrm{~h}$ were considered. Note that the neutral axis was shifted toward the compression side at $1000 \mathrm{~h}$, which is in good agreement with frequent observations for uniaxial flexure specimens of various advanced ceramics [1-3,21-23]. Generation of more creep database as well as subsequent verifications of the design code are needed for better establishment of creep deformation/life assessment methodology.

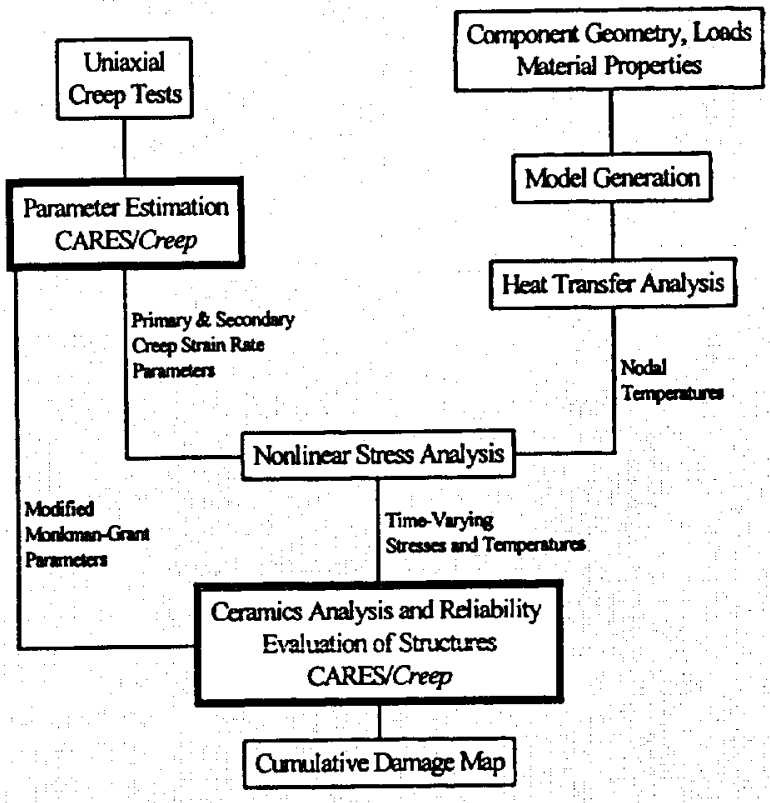

Figure 5. Block diagram for the creep analysis of a monolithic ceramic component using the CARES/Creep design code

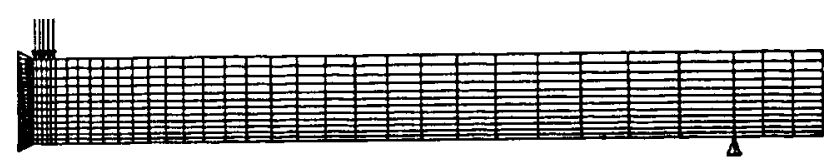

Figure 6. Fine element meshes employed in CARES/Creep predictions

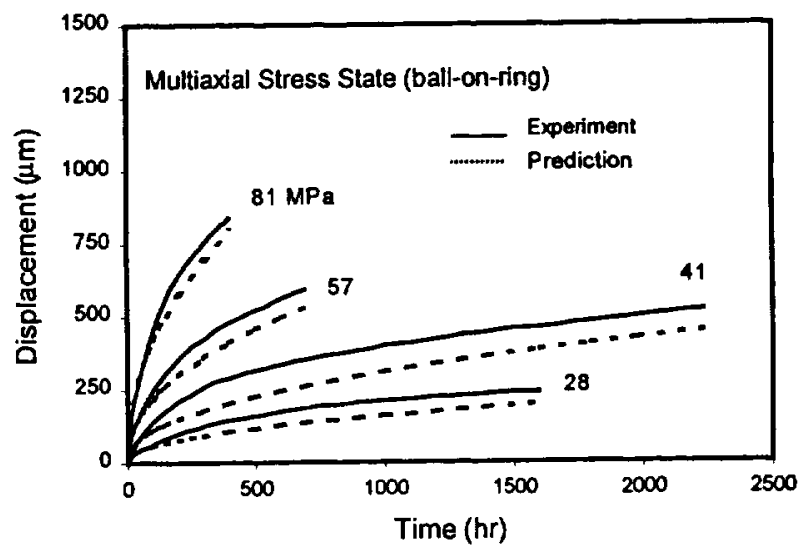

Figure 7. CARES/Creep predictions of creep displacements for multiaxial stress state in ball-on-ring flexure at five different nominal stresses. The experimental data were included for comparison. 


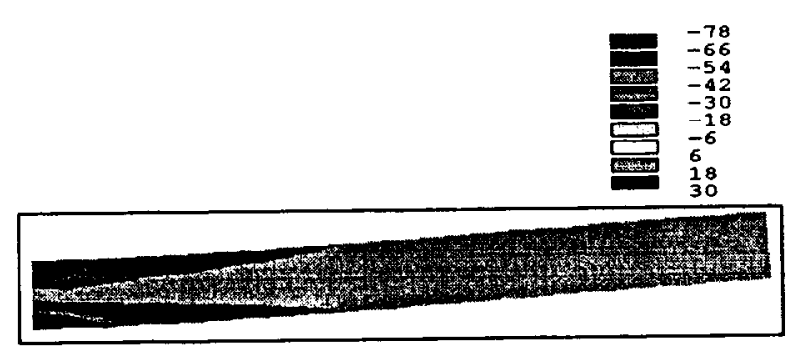

(a) $\mathrm{t}=0$

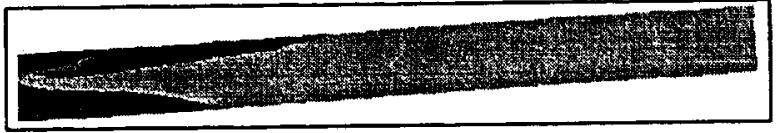

(b) $\mathrm{t}=1000 \mathrm{hr}$

Figure 8. Change in the state of stress for the ball-on-ring disk specimen from time $\mathrm{t}=0 \mathrm{to} \mathrm{t}=1000 \mathrm{hr}$. The nominal applied stress was $28 \mathrm{MPa}$. Note that the neutral axis was shift toward the compression side at $1000 \mathrm{hr}$.

\section{CONCLUSIONS}

Creep testing of a hot-pressed silicon nitride ( $\mathrm{NC1} 32$ silicon nitride) was carried out using five different specimen-loading configurations at $1300^{\circ} \mathrm{C}$ in air. The specimen-loading configurations used included pure tension, pure compression, four-point uniaxial flexure, ball-on-ring biaxial flexure, and ringon-ring biaxial flexure. Except for compression loading, nominal creep strain rate decreased gradually with time, resulting in lessdefined steady-state condition. The magnitude and the rate of nominal creep strain for a given nominal applied stress were greatest in tension, least in compression, and intermediate in uniaxial and biaxial flexure. In flexure loading, uniaxial flexure was greater in creep strain than biaxial flexure.

Four different creep models - power-law, hyperbolic sine, step, and redistribution models - were applied to the experimental data. All of the models gave a reasonable data fit, unclear which would be most appropriate for the $\mathrm{NC132}$ material. The conventional power-law model showed an overall stress exponent of about 2 (ranging from 1.7 to 2.5 ) irrespective of specimen-loading configurations. Predictions of creep deformation in response to multiaxial (biaxial) stress state, made utilizing the CARES/Creep design code, were in reasonable agreement with the actual experimental data.

\section{Acknowledgements}

The authors are grateful to R. Pawlik for the experimental work during the course of this study. This work was sponsored in part by Strategic Research Fund Program, Glenn Research Center, National Administration of Space and Aeronautics, Cleveland, Ohio.

\section{REFERENCES}

1. S. M. Wiederhorn, D. E. Roberts, T.J. Chuang, and L. Chuck, Damage-Enhanced Creep in a Siliconized Silicon Carbide: Phenomenology, J. Am. Ceram. Soc., 71[7] (1988) 602-608.

2. M. K. Ferber, M. G. Jenkins, and V. J. Tennery, Comparison of Tension, Compression, and Flexure Creep for Alumina and Silicon Nitride Ceramics, Ceram. Eng. Sci. Proc., 11[7-8] (1990) 1028-1045.

3. T. J. Chuang, Estimation of Power-Law Creep Parameters from Bend Test Data, J. Mater. Sci., 21 (1986) 165-175.

4. O. M. Jadaan, L. M. Powers, and J. P. Gyekenyesi, Creep Life Prediction of Ceramic Components Subjected to Transient Tensile and Compressive Stress States, ASME Paper \# 97-GT-319 (1977).

5. L. M. Powers, O. M. Jadaan, and J. P. Gyekenyesi, Creep Life of Ceramic Components Using a Finite-Element-
Based Integrated Design Program, Trans. of ASWE J. Eng. for Gas Turbines \& Power, 120 (1998) \$62-171.

6. G. D. Quinn and J. B. Quinn, Slow Crack Growth in HotPressed Silicon Nitride, Fracture Mechanics of Ceramics, vol. 6, R.C. Bradt, A. G. Evans, D.P.H. Hasselman, and F.F. Lange, Eds., Plenum Publishing Corp., NY (1983) 603-635.

7. D. G. Miller et al., Brittle Materials Design, High Temperature Gas Turbine Material Technology, AMMRC CTR 76-32, Army Materials \& Mechanics Research Center, Watertown, MA (1976).

8. R. K. Govila, Ceramic Life Prediction Parameters, AMMRC TR 80-18, Army Materials \& Mechanics Research Center, Watertown, MA (1980).

9. S. R. Choi and F. A. Holland, Silicon Nitride Creep under Various Specimen-Loading Configurations, NASA TM 210026-0, National Aeronautics \& Space Administration, Glenn Research Center, Cleveland, $\mathrm{OH}(2000)$.

10. ASTM C 1291, Standard Test Method for Elevated Temperature Tensile Creep Strain, Creep Strain Rate, and Creep Time-to-Failure for Advanced Monolithic Ceramics, Annual Book of ASTM Standards, vol. 15.01, American Society for Testing \& Materials, Philadelphia, PA (2000).

11. J. M. Birch, B. Wilshire, D.J.R. Owen, and D. Shantaram, The Influence of Stress Distribution on the Deformation and Fracture Behavior of Ceramic Materials under Compression Creep Conditions, J. Mater. Sci., 11 (1976) 1817-1825.

12. D. K. Shetty, A. R. Rosenfield, P. McGuire, G. K. Bansal, and W. H. Duckworth, Biaxial Flexure Test for Ceramics, Am. Cerm. Soc. Bull,. 59[12] (1980) 1193-1197.

13. D. S. Wilkinson, Creep Mechanisms in Multiphase Ceramic Materials, J. Am. Ceram. Soc., 81[2] (1998) 275299.

14. F. H. Norton, Creep of Steel at High Temperatures, McGraw Hill, New York, NY (1929).

15. Nadai, The Influence of Time upon Creep; The Hyperbolic Sine Creep Law, in S. Timoshenko Anniversary Volume, McMillian, New York, NY (1938).

16. R. M. Hazine and C. S. White, Multiaxial Internal Variable Modeling of the Creep Deformation and Fracture of an Advanced Silicon Nitride, Ceram. Eng. Sci. Proc., 18[3] (1997) 455-465.

17. C. W. Li and F. Reidinger, Microstructure and Tensile Creep Mechanisms of an In situ Reinforced Silicon Nitride, Acta Mater., 45[1] (1997) 407-421.

18. R. F. Krause, W. E. Luecke, J. D. French, B. J. Hockey, and S. M. Wiederhorn, Tensile Creep and Rupture Silicon Nitride, J. Am. Ceram. Soc., 82[5] (1999) 1233-1241.

19. W. G. Cannon and T. G. Langdon, Review: Creep of Ceramics. Part 1 Mechanical Characteristics, J. Mater. Science, 18 (1981) 1-50.

20. W. G. Cannon and T. G. Langdon, Review: Creep of Ceramics. Part 2 An Examination of Flow Mechanisms, J. Mater. Sci., 23 (1988) 1-20.

21. J. A. Salem and S. R. Choi, Creep Behavior of Silicon Nitride Determined from Curvature and Neutral Axis Shift Measurements in Flexure Tests" Life Prediction Methodologies and data fro ceramic Materials, ASTM STP 1201, C. R. Brinkman and S. F. Duffy, Eds., American Society for Testing and materials, Philadelphia, (1994) 84-97.

22. S. R. Choi and J. A. Salem, Creep Behavior of Silicon Nitride Evaluated by Deformation Curvature and Neutral Axis Shift Determination, Silicon-Based Structural Ceramics, B. W. Sheldon and S. C. Danforth eds., Ceramic Transactions, 42 (1994) 285-293.

23. K. Jakus and S. M. Wiederhom, Creep Deformation of Ceramics in Four-Point Bending, $J$. Am. Ceram. Soc., 71[10] (1988) 196-199.

24. S. R. Choi, L. M. Powers, and J. P. Gyekenyesi, Creep Behavior of Silicon Nitride with Various Specimen/Loading Configurations, and Creep Prediction Using the CARES/Creep Program, Proc. of the 1" China International Conference on High-Performance Ceramics (CICC-1), Tsinghua University Press, Beijing, China (1999) 612-615. 